\title{
DETERMINATION OF THE SPECIFIC ZONE RESISTANCE AND CALCU- LATION OF THE RESPONSE FACTOR IN ISOTACHOPHORESIS
}

\section{J. L. BECKERS and F. M. EVERAERTS*}

Laboratory of Instrumental Analysis, Eindhoven Uinversity of Technology, P.O. Box 513, 5600 MB Eindhoven (The Netherlands)

(First received December 18th, 1988, revised manuscript received January 19th, 1989)

\section{SUMMARY}

If the electric current density applied in isotachophoresis (ITP) experiments is not too high, a linear relationship between the step heights (using an a.c. detector) and the specific zone resistance at $25^{\circ} \mathrm{C}\left(\mathrm{SZR}_{25}\right)$ is obtained. In this way the $\mathrm{SZR}_{25}$ of a substance in ITP experiments can be obtained using two standard substances for which the $\mathrm{SZR}_{25}$ values can be calculated using the mathematical model for the steady state in ITP. From the step heights of these two standards a linear relationship between step height and $\mathrm{SZR}_{25}$ can be set up and from this relationship and the step height of an ionic species its $\mathrm{SZR}_{25}$ can be calculated. From the $\mathrm{SZR}_{25}$ values all qualitative parameters such as the absolute mobility of the substances can be calculated. Hence no corrections for the differences in the temperature of the different zones have to be made. The absolute mobilities obtained show good agreement with literature values. If the absolute mobility and $\mathrm{p} K$ value of a substance are known, the response factor, RF, can be calculated; this is useful for quantitative determinations, in which case calibration graphs are not necessary. RF values were calculated and determined experimentally for several leading electrolyte systems. An average accuracy of about $3 \%$ can be obtained in practice.

\section{INTRODUCTION}

In a related paper, Gladdines et al. ${ }^{1}$ proposed the concept of the dimensionless response factor (RF), defined as:

$$
\mathrm{RF}=t_{i} I /|z| F Q
$$

with $t_{i}$ is the zone length (s), $I$ the applied electric current (A), $|z|$ the valence of the ionic species (in equiv./mol ), $F$ the Faraday constant (C/equiv.) and $Q$ the amount of the sample ionic species (mol).

The RF value is a universal constant useful for quantitative determinations in isotachophoresis (ITP), independent of the apparatus used (e.g., diameter of the cap- 
illary tube and detector) and electric current applied ${ }^{a}$. The RF value was used for the analysis of intravenous injection solutions for 26 drugs and an accuracy of $2-3 \%$ was obtained.

This concept of the RF is especially interesting because it can easily be calculated with a steady-state model for ITP if the absolute mobility ${ }^{b}$ and $\mathrm{p} K$ value of the sample substances are known. From the measured step heights in ITP, the absolute mobilities and $\mathrm{p} K$ values of substances can be calculated with the concept of the isoconductor ${ }^{2}$. This means that from a single experiment (if the $p K$ value is known) or from two experiments in two different leading electrolyte systems (if the mobility and $\mathrm{p} K$ are unknown), from the step heights the absolute mobility and/or $\mathrm{p} K$ value of an unknown sample substance can be calculated and hence, calculating the RF, the amount of sample can be obtained from the measured zone lengths. This powerful technique is based on the fact that in ITP the separation mechanism is well defined and the step height contains all qualitative and the zone length all quantitative information.

Using the concept of the isoconductor, the zone resistances must be obtained from the measured step heights. These step heights (zone resistances), however, depend on the type of apparatus (e.g., type of detector and diameter of the capillary tube) and applied electric current (e.g., temperature and condition of the measuring electrodes). Some workers therefore use $R_{\mathrm{F}}$ values $^{3}, P U$ values ${ }^{4}$ and relative step heights ${ }^{5}$ to standardize the step heights. Although, e.g., $R_{\mathrm{E}}$ and $P U$ values can be used satisfactorily with potentiometric detectors, they are not suitable with a.c. detectors, although these parameters can be calculated from a.c. data. Gas et $a l^{6}{ }^{6}$ presented a method for the measurement of mobilities by regulating the electric current applied in such a way that the thermal power at the detection site is constant and a constant temperature is created, so that corrections for the differences in temperature are superfluous.

In this paper we present a method for determining the specific zone resistance (S7R) at $25^{\circ} \mathrm{C}$ from two standard step heights. I Jing the concept of the isoconductor, absolute mobilities can be calculated. Further, it is shown how the RF can be calculated if the mobility and $\mathrm{p} K$ values of sample substances are known, and theoretical $\mathrm{RF}$ values are compared with those obtained experimentally.

\section{THEORETICAL}

If in ITP experiments the steady state is reached, all sample ionic species migrate with equal velocity and a well defined concentration in consecutive zones. For an ionic species $i$ this means that

$$
Q_{i}=l_{i} A c_{i}
$$

where $Q_{i}$ is the amount of sample, $l_{i}$ the zone length $(\mathrm{m}), A$ the surface area of the

\footnotetext{
"This is true only for not too large differences in the elcctric current, otherwise too large differences in zone temperatures can cause large differences in temperature-dependent parameters such as the mobilities and $\mathrm{p} K$ values.

${ }^{b}$ By absolute mobility, always the ionic mobility at infinite dilution is meant.
} 
capillary tube $\left(\mathrm{m}^{2}\right)$ and $c_{i}$ the total concentration in the zone $\left(\mathrm{mol} / \mathrm{m}^{3}\right)$. The time $t_{i}(\mathrm{~s})$ needed to pass the detector will be

$$
t_{i}=l_{i} / v_{i}
$$

where $v_{i}$ is the ITP velocity $(\mathrm{m} / \mathrm{s})$. Because

$$
v_{i}=m_{i} E_{i}
$$

where $m_{i}$ is the effective mobility of the substance $\left(\mathrm{m}^{2} / \mathrm{Vs}\right)$ and $E_{i}$ the electric field strength in the zone $(\mathrm{V} / \mathrm{m})$, eqn. 3 can be written as

$$
t_{i}=Q_{i} / A c_{i} m_{i} E_{i}
$$

Using the equation

$$
E_{i}=I \rho_{i} / A
$$

where $I$ is the electric current (A) and $\rho_{i}$ the specific zone resistance $(\Omega \mathrm{m})$, eqn. 5 can be written as

$$
t_{i}=Q_{i} / c_{i} m_{i} I \rho_{i}
$$

or

$$
t_{i} I / Q_{i}=1 / c_{i} m_{i} \rho_{i}
$$

In fact this is the RF $(\mathrm{C} / \mathrm{mol})$ and it represents the slope of a calibration graph of the product $t_{i} I(\mathrm{sA})$ versus the amount of the sample, $Q_{i}$.

Although for strong electrolytes the definition of Gladdines et al. ${ }^{1}$ (eqn. 1) is applicable, it is preferable to use the $\mathrm{RF}$ in $\mathrm{C} / \mathrm{mol}$ in order to avoid working with an "average charge $z$ " for multi-valent weak electrolytes. With a steady-state model for ITP, all zone parameters, including $c_{i}, m_{i}$ and $\rho_{i}$ can be calculated, from which the RF value can be obtained.

It must be noted that the formulation of the universal quantitative parameter RF has already been used implicitly and calculated for 287 anionic species by Hirokawa et al. ${ }^{3}$ using the parameter $t$ (ref. 3 , Table IV), which is the time-based zone length (s) for 10 -nmol samples at a driving current of $100 \mu \mathrm{A}$. Hence the RF value $(\mathrm{C} / \mathrm{mol})$ will be $t \cdot 10^{4}$.

\section{APPARATUS}

In order to obtain quantitative data, isotachophoretic equipment developed and built by Everaerts et al. ${ }^{5}$ was used. The separation compartments consisted of capillary tubes of both 0.4 and $0.2 \mathrm{~mm}$ I.D. The d.c. current was taken from a modified Brandenburg (Thornton Heath, U.K.) high-voltage power supply. The 
zones were detected with a laboratory-made high-performance a.c. conductivity detector.

For the qualitative data, isotachophoretic equipment as described elsewhere ${ }^{7}$ was used. In this equipment a casted separation and detection unit is used, through which optimum heat transfer leads to minimum temperature differences between the consecutive zones.

\section{EXPERIMENTAL}

In order to calculate the mobilities of ionic species using the concept of the isoconductor ${ }^{2}$, the zone resistances must be obtained from the measured step heights. These step heights (zone resistances), however, depend on the type of apparatus (e.g., type of detector and diameter of the capillary tube) and applied electric current (e.g., temperature and condition of the measuring electrodes). First we checked the expected linear relationship between the measured step heights and SZR using the a.c. detector, by measuring the step heights for several dilute solutions of potassium chloride, the SZR of which are precisely known at $25^{\circ} \mathrm{C}$, without applying an electric current. The relationship obtained is shown in Fig. 1 for an ITP apparatus with a capillary tube of $0.4 \mathrm{~mm}$ I.D. On applying different electric currents, heat will be produced so that all measurements on standard solutions of potassium chloride, even with a thermostated apparatus, will be made at different temperatures, resulting in lower step heights. Corrections for these temperatures are difficult as they are not known exactly.

However, the relationship set up between the measured step heights (for a specific electric current) and the SZR of the potassium chloride solutions at $25^{\circ} \mathrm{C}$ $\left(S Z R_{25}\right)$ can be used to determine the $\mathrm{SZR}_{25}$ of other substances. Because all ionic species show very similar temperature dependences of their mobilities, it can be assumed that ionic species with a SZR (step height) equal to that of a specific potassium chloride solution will have identical temperatures during the measurement and will have an identical $\mathrm{SZR}_{25}$.

In Fig. 1 the relationships between step heights and $S Z R_{25}$ values for different

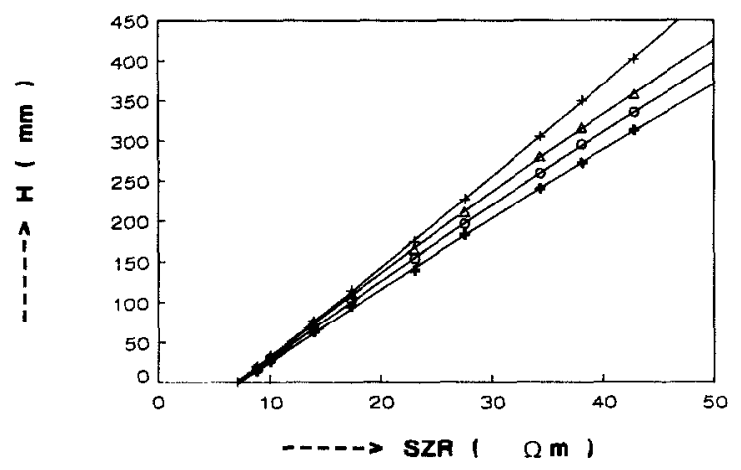

Fig. 1. Relationships between measured step heights $(H)$ and the specific zone resistance (SZR) at $25^{\circ} \mathrm{C}$ of different $\mathrm{KCl}$ solutions for applied electric currents of $(+) 0,(\triangle) 40,(\bigcirc) 80$ and $(+) 120 \mu \mathrm{A}$. I.D. of capillary tube, 0.4 inm 
potassium chloride solutions are given for several electric currents, which can be used to determine the $\mathrm{SZR}_{25}$ of components from ITP measurements. Over a wide range of SZR 25 values a linear relationship is obtained, although for very dilute solutions of potassium chloride too low step heights were obtained, possibly owing to a high heat production, resulting in higher temperatures.

In Table I the calculated $\mathrm{SZR}_{25}$ values of potassium chloride solutions and the measured step heights (for capillary tubes of both 0.4 and $0.2 \mathrm{~mm}$ I.D.) are given for the different electric currents. The $\mathrm{SZR}_{25}$ values were calculated using the DebyeHuckel-Onsager relationship ${ }^{8}$.

$$
\Lambda=\Lambda^{\circ}-\left(a+b \Lambda^{\circ}\right) \sqrt{ } c
$$

for water at $25^{\circ} \mathrm{C}, a=60.20 \Omega^{-1} \mathrm{~cm}^{2} \mathrm{~mol}^{-1}\left(\mathrm{~mol} \mathrm{dm}^{-3}\right)^{-0.5}$ and $b=0.229(\mathrm{~mol}$ $\left.\mathrm{dm}^{-3}\right)^{-0.5}$. For $\mathrm{KCl} \Lambda^{\circ}=149.86 \Omega^{-1} \mathrm{~cm}^{2} \mathrm{~mol}^{-1}$.

\section{Determination of $S Z R_{25}$ in $\Omega m$}

From the above, it can be concluded that for not too high electric currents and ionic species of not too low mobility, a linear relationship between the step heights and SZR $_{25}$ can be expected (of course, the diameter of the capillary tube and the cooling capacity of the detector system also play an important part). Hence the $\mathrm{SZR}_{25}$ of a substance can be obtained using two standard substances for which the $\mathrm{SZR}_{25}$ values can be calculated (based on the mathematical model for the steady state in ITP). From the step heights of these two standard substances, the linear relationship between step height and $\mathrm{SZR}_{25}$ can be set up and from this relationship and the step height of an ionic species its $\mathrm{SZR}_{25}$ can be calculated. The $\mathrm{SZR}_{25}$ values obtained are used as experimental parameters for the calculation of the absolute mobil-

\section{TABLE I}

MEASURED STEP HEIGHTS AND CALCULATED SZR $_{25}$ VALUES FOR POTASSIUM CHLORIDE SOLUTIONS FOR SEVERAL APPLIED ELECTRIC CURRENTS AND CAPILLARY TUBES OF 0.4 AND $0.2 \mathrm{~mm}$ I.D.

\begin{tabular}{|c|c|c|c|c|c|c|c|}
\hline \multirow{3}{*}{$\begin{array}{l}\text { KCl concentration } \\
(\text { molll })\end{array}$} & \multirow{3}{*}{$\begin{array}{l}S Z R_{25} \\
(\Omega \mathrm{m})\end{array}$} & \multicolumn{6}{|c|}{ Step height $(\mathrm{mm})$} \\
\hline & & \multicolumn{4}{|c|}{ I.D. $0.4 \mathrm{~mm}$} & \multicolumn{2}{|c|}{ I.D. $0.2 \mathrm{~mm}$} \\
\hline & & $0 \mu \mathrm{A}$ & $40 \mu A$ & $80 \mu A$ & $I 20 \mu A$ & $0 \mu A$ & $20 \mu A$ \\
\hline 0.0100 & 7.122 & 0 & -0.5 & -1.9 & -4.0 & 0 & -0.2 \\
\hline 0.0080 & 8.840 & 19.6 & 18.9 & 17.0 & 14.1 & 3.8 & 3.5 \\
\hline 0.0070 & 10.064 & 33.5 & 32.3 & 30.0 & 26.5 & 6.7 & 6.2 \\
\hline 0.0050 & 13.970 & 76.7 & 73.6 & 67.0 & 62.5 & 15.9 & 14.7 \\
\hline 0.0040 & 17.375 & 115.0 & 110.8 & 103.5 & 95.5 & 24.5 & 23.0 \\
\hline 0.0030 & 23.039 & 174.5 & 165.0 & 153.3 & 139.0 & 39.5 & 36.8 \\
\hline 0.0025 & 27.561 & 227.0 & 211.0 & 196.0 & 183.0 & 51.5 & 48.0 \\
\hline 0.0020 & 34.333 & 305.0 & 280.0 & 259.0 & 240.0 & 70.8 & 66.0 \\
\hline 0.0018 & 38.091 & 350.0 & 316.0 & 295.0 & 272.0 & 82.5 & 77.0 \\
\hline 0.0016 & 42.785 & 402.0 & 358.0 & 335.0 & 313.0 & 96.8 & 91.8 \\
\hline 0.0014 & 48.820 & 473.0 & 415.0 & 390.0 & 360.0 & 116.5 & 110.0 \\
\hline
\end{tabular}


ities of sample ionic species and these can be used to calculate the RF values. As standard substances both the leading ions, terminating or other ionic species can be used. For substances of very low mobility standards can be chosen with mobilities close to that of the sample component. In our calculations, corrections for the concentration dependence of the mobilities and for activities were made.

To check the accuracy of this method for the determination of the $\mathrm{SZR}_{25}$ values and the calculation of absolute mobilities, we measured the step heights of some anions using several leading electrolytes. In Table II the $\mathrm{p} K$ values and absolute mobilities of the leading, counter and standard ionic species used in the calculations are given. In Table III the absolute mobilities calculated from the experimentally obtained step heights are given. All leading electrolyte solutions were prepared by adding the counter ionic species to $0.01 \mathrm{M}$ hydrochloric acid until the $\mathrm{pH}_{\mathrm{L}}$ was reached. The counter ionic species for the solutions were histidine $\left(\mathrm{pH}_{\mathrm{L}}=6.08\right)$, creatinine $\left(\mathrm{pH}_{\mathrm{L}}=4.75\right)$ and $\beta$-alanine $\left(\mathrm{pH}_{\mathrm{L}}=4.40,3.73\right.$ and 3.71). All values given in Table III were measured twice; the differences between the duplicates were less than $1 \%$. The differences between the absolute mobilities obtained from different electrolyte systems are often larger, especially with low $\mathrm{pH}_{\mathrm{r}}$, values. In such a case the accuracy of both the $\mathrm{pH}_{\mathrm{L}}$ and the $\mathrm{p} K$ values is very important. As an example, the absolute mobility of phenylacetic acid was calculated with a $\mathrm{p} K$ value of 4.41 (ref. 3 ) and 4.28 (ref. 9); the mobilities with the $\mathrm{p} K$ value of 4.28 were significantly better.

As standards the leading ion chloride and acetate were always used and the electric current was $15 \mu \mathrm{A}$, except for the system at $\mathrm{pH}_{\mathrm{L}}=3.71$, where the standards were chloride and propionate and the electric current was $10 \mu \mathrm{A}$. This was done because in the systems at low pH the SZR are relatively high (about $50 \Omega \mathrm{m}$ ) compared

\section{TABLE II}

$\mathrm{p} K$ VALUES AND ABSOLUTE MOBILITIES FOR LEADING, COUNTER AND STANDARD IONIC SPECIES USED IN THE CALCULATIONS

\begin{tabular}{lll} 
Ionic species & $\begin{array}{l}\text { Mobility } \\
\left(10^{-5} \mathrm{~cm}^{2} / V \cdot s\right)\end{array}$ \\
\hline Acetate & 42.4 & 4.756 \\
p-Aminobenzoate & 31.6 & 4.853 \\
$\beta$-Alanine & 36.7 & 3.552 \\
Chlorate & 67.0 & -2.7 \\
Chloride & 79.1 & -2.0 \\
Creatinine & 37.2 & 4.828 \\
2,4-Dihydroxybenzoate & 32.0 & 3.395 \\
Formate & 56.6 & 3.75 \\
Histidine & 29.6 & 6.04 \\
Imidazole & 52.0 & 7.15 \\
Lithium & 40.1 & 14 \\
Nitrate & 74.0 & -2 \\
Potassium & 76.2 & 14 \\
Propionate & 37.1 & 3.75 \\
Sodium & 51.9 & $>7$ \\
Tetramethylammonium & 44.3 & $>7$ \\
Tetraethylammonium & 32.7 & \\
\hline
\end{tabular}


TABLE III

CALCULATED ABSOLUTE MOBILITIES FROM SZR ${ }_{25}$ VALUES, OBTAINED FROM MEASURED STEP HEIGHTS IN ELECTROLYTE SYSTEMS AT DIFFERENT pH VALUES

The electric current applied was $15 \mu \mathrm{A}$, except for the system at $\mathrm{pH}_{\mathrm{L}}=3.71$, where it was $10 \mu \mathrm{A}$. For further explanation, see text.

\begin{tabular}{|c|c|c|c|c|c|c|c|}
\hline \multirow[t]{3}{*}{ Ionic species } & \multirow[t]{3}{*}{$p K$} & \multicolumn{6}{|c|}{ Absolute mobility $\left(10^{-5} \mathrm{~cm}^{2} / \mathrm{V} \cdot \mathrm{s}\right)$} \\
\hline & & \multirow[t]{2}{*}{ I.it. 3.10} & \multicolumn{5}{|c|}{ Experimentally determined } \\
\hline & & & 6.08 & 4.75 & 4.40 & 3.73 & 3.71 \\
\hline Chloric acid & -2.7 & 67.0 & 66.9 & 66.0 & 66.5 & 67.7 & 66.0 \\
\hline Chloroacetic acid & 2.87 & 43.7 & 40.4 & 40.1 & 40.3 & 42.1 & 40.9 \\
\hline 2,4-Dihydroxybenzoic acid & 3.40 & 32.0 & 30.9 & 30.2 & 30.9 & 32.6 & 32.1 \\
\hline Glutamic acid & 4.38 & 28.9 & 28.3 & 28.5 & 29.0 & 29.8 & 29.5 \\
\hline Glycolic acid & 3.89 & 42.4 & 42.4 & 41.6 & 42.4 & 43.9 & 43.7 \\
\hline Glyoxilic acid & 3.34 & 39.6 & $a^{a}$ & 39.2 & 39.9 & 40.8 & 40.7 \\
\hline Hydrofluoric acid & 3.17 & 57.4 & 57.0 & 56.8 & 57.2 & 57.8 & 57.5 \\
\hline Hydroxyphenylacetic acid & 3.17 & 26.9 & 30.5 & 29.2 & 28.9 & 29.6 & 28.2 \\
\hline$o$-Aminobenzoic acid & 4.94 & 31.6 & 32.8 & 32.2 & - & 31.7 & 31.3 \\
\hline$o$-Methoxybenzoic acid & 4.09 & 28.3 & 30.3 & 29.3 & 30.3 & 31.0 & 30.5 \\
\hline Nitric acid & -1.37 & 74.1 & 74.3 & 75.1 & 74.1 & 75.3 & 74.0 \\
\hline \multirow[t]{2}{*}{ Phenylacetic acid } & 4.41 & 31.7 & 30.9 & 30.5 & 32.6 & 34.2 & - \\
\hline & 4.28 & - & 30.8 & 30.0 & 30.6 & 30.9 & 30.5 \\
\hline Phenylglyoxilic acid & $-^{b}$ & - & 33.4 & 32.0 & 32.1 & 33.8 & 32.5 \\
\hline Propionic acid & 4.87 & 37.1 & 37.1 & 37.5 & 38.1 & 36.9 & 37.1 \\
\hline Sulphosalycilic acid & $--^{b}$ & - & 54.5 & 53.7 & 55.1 & 55.6 & 54.6 \\
\hline Trimethylacetic acid & 5.04 & 31.8 & 30.9 & 31.7 & 31.9 & 31.5 & 32.1 \\
\hline
\end{tabular}

${ }^{a}$ Sloping step height.

${ }^{b}$ Considered to be fully ionized.

TABLE IV

\section{CALCULATED AND EXPERIMENTALLY DETERMINED RF VALUES}

For all experimental values the number of measuring points $(N)$, regression coefficient and $R F$ values are given. For further explanation, see text.

\begin{tabular}{|c|c|c|c|c|c|c|c|c|}
\hline \multirow[t]{2}{*}{$p H$} & \multirow{2}{*}{$\begin{array}{l}\text { Ionic } \\
\text { species }\end{array}$} & \multirow[t]{2}{*}{ Ref. } & \multirow[t]{2}{*}{$N$} & \multirow{2}{*}{$\begin{array}{l}\text { Regression } \\
\text { coefficient }\end{array}$} & \multicolumn{3}{|c|}{$R F\left(10^{5} \mathrm{C} / \mathrm{mol}\right)$} & \multirow{2}{*}{$\begin{array}{l}\text { Deviation } \\
(\%)\end{array}$} \\
\hline & & & & & Calc. & Ref.3 & Exptl. & \\
\hline 6 & Acetate & 11 & 3 & 0.9997 & 1.622 & 1.622 & 1.670 & +3.0 \\
\hline 7 & Acetate & 11 & 3 & 1.0000 & 2.163 & 2.161 & $2.19 I$ & +1.3 \\
\hline 7 & Formate & 11 & 3 & 0.9993 & 1.848 & 1.848 & 1.883 & +1.9 \\
\hline 6 & Acetate & 11 & 20 & 0.9997 & 1.622 & 1.622 & 1.675 & +3.3 \\
\hline 6 & Formate & 11 & 20 & 0.9996 & 1.447 & 1.448 & 1.424 & -1.6 \\
\hline 6 & 2,4-Dihydroxybenzoate & & 5 & 0.9998 & 1.856 & 1.853 & 1.924 & +3.7 \\
\hline 6 & p-Aminobenzoate & & 3 & 0.9984 & 1.868 & 1.865 & 1.785 & -4.4 \\
\hline 4.5 & TMA & & 13 & 0.9977 & 1.938 & - & 1.840 & -5.1 \\
\hline 4.5 & TEA & & 13 & 0.9994 & 2.350 & - & 2.264 & -3.7 \\
\hline 4.5 & Sodium & & 13 & 0.9998 & 1.781 & - & 1.744 & -2.1 \\
\hline 4.5 & Barium & & 8 & 0.9998 & 3.263 & - & 3.24 & -0.7 \\
\hline 4.5 & Imidazole & & 8 & 0.9993 & 1.809 & - & 1.753 & -3.1 \\
\hline 4.5 & Lithium & & 8 & 0.9997 & 2.055 & - & 2.00 & -2.7 \\
\hline
\end{tabular}


with those of the other systems. A comparison with the literature values ${ }^{3.10}$ showed good agreement.

\section{Calculated and determined RF values}

In order to check the applicability of the RF values, we compared calculated and experimentally obtained RF values. In Table IV the calculated RF value (with eqn. 8), the value of $t \cdot 10^{4}$ (ref. 3) and experimental values are given for a number of ionic species. The deviation is calculated as follows:

$$
\text { Deviation }(\%)=\left(\mathrm{RF}_{\mathrm{exp}}-\mathrm{RF}_{\text {calc }}\right) / \mathrm{RF}_{\text {calc }} \cdot 100 \%
$$

For all calibration graphs the number of data points $(N)$ and the regression coefficients are given. The calculated values and the values of $t \cdot 10^{4}$ are nearly equal although small differences arise owing to differences in the corrections to $\mathrm{p} K$ values and absolute mobilities in the calculations. The experimental data from ref. 11 measured with a thermometric detector also fit well.

Although the impact of the use of RF values is large, the differences between the experimentally determined and calculated RF values are fairly high (average deviation $3 \%$ ), although the differences of $-5.1 \%$ (TMA) and $-3.7 \%$ (TEA) are possibly due to inaccurate absolute mobilities and that of $-4.4 \%$ ( $p$-aminobenzoic acid) may be due to the impurity of this substance.

The practical value of the RF data will depend strongly on both the accuracy of the measurement of the electric current and the accuracy of the preparation of the sample solutions. For example, for the measurement of the RF value of $\mathrm{Li}^{+}$we prepared a stock solution using lithium nitrate. The RF value agrees well with the calculated value. In the first instance, however, we prepared twice a stock solution from undried lithium chloride. The experimentally obtained RF values were 1.66 and

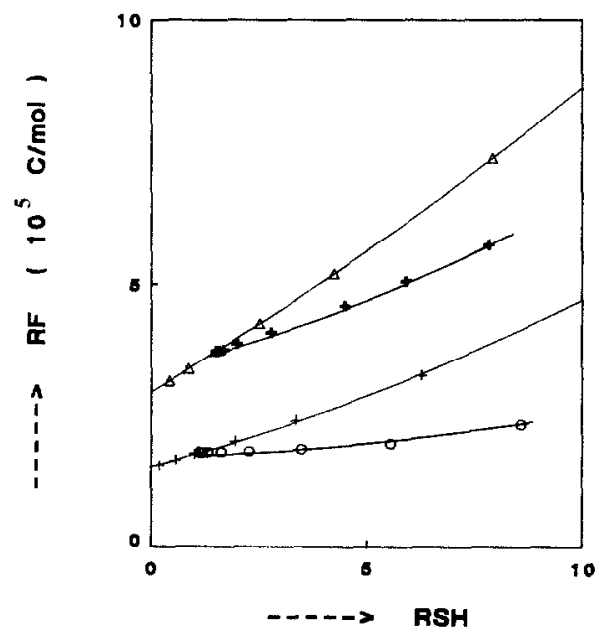

Fig. 2. Relationship between calculated RF values and RSH for $(+)$ strong monovalent, $(\Delta)$ strong divalent, $(O)$ weak monovalent and $(+)$ weak divalent cationic species. Leading electrolyte, $0.01 M \mathrm{KOH}$ at pII 5, adjusted by adding acetic acid. 
1.65, respectively. After drying the lithium chloride an RF value of 1.91 was obtained, showing the importance of sample preparation.

Of course, theoretical RF values cannot be used when complex formation occurs or other factors that affect the effective mobility of the sample ionic species arise, if appropriate corrections are not made in the computer program.

For a further comparison, the theoretical relationship between calculated RF values and calculated RSH values (relative step heights calculated using the standard

\section{TABLE V}

CALCULATED RSH AND RF VALUES FOR STRONG AND WEAK MONOVALENT AND DIVALENT CATIONS USING A LEADING ELECTROLYTE 0F 0.01 $M$ POTASSIUM HYDROXIDE AND ACETIC ACID AT A pH OF 5

For further explanation, see text.

\begin{tabular}{|c|c|c|c|c|}
\hline Valency & $\begin{array}{l}\text { Absolute mobility } \\
\left(10^{-5} \mathrm{~cm}^{2} / \mathrm{V} \cdot \mathrm{s}\right)\end{array}$ & $p K$ & $\begin{array}{l}\text { Calculated } R F \text { value } \\
\left(10^{5} \mathrm{C} / \mathrm{mol}\right)\end{array}$ & $R S H$ \\
\hline \multirow[t]{6}{*}{1} & 70 & 14 & 1.549 & 0.1875 \\
\hline & 60 & 14 & 1.641 & 0.574 \\
\hline & 50 & 14 & 1.787 & 1.121 \\
\hline & 40 & 14 & 2.012 & 1.951 \\
\hline & 30 & 14 & 2.4035 & 3.360 \\
\hline & 20 & 14 & 3.251 & 6.254 \\
\hline \multirow[t]{6}{*}{2} & 70 & 14 & 3.139 & 0.428 \\
\hline & 60 & 14 & 3.370 & 0.876 \\
\hline & 50 & 14 & 3.706 & 1.519 \\
\hline & 40 & 14 & 4.236 & 2.511 \\
\hline & 30 & 14 & 5.190 & 4.239 \\
\hline & 20 & 14 & 7.388 & 7.912 \\
\hline \multirow[t]{11}{*}{1} & 50 & 9 & 1.787 & 1.121 \\
\hline & 50 & 8 & 1.787 & 1.123 \\
\hline & 50 & 7 & 1.788 & 1.143 \\
\hline & 50 & 6.5 & 1.789 & 1.189 \\
\hline & 50 & 6 & 1.791 & 1.318 \\
\hline & 50 & 5.5 & 1.797 & 1.627 \\
\hline & 50 & 5 & 1.811 & 2.272 \\
\hline & 50 & 4.5 & 1.849 & 3.476 \\
\hline & 50 & 4 & 1.954 & 5.544 \\
\hline & 50 & 3.5 & 2.330 & 8.584 \\
\hline & 50 & 3 & 6.044 & 10.110 \\
\hline \multirow[t]{10}{*}{2} & 50 & 9 & 3.706 & 1.519 \\
\hline & 50 & 8 & 3.706 & 1.520 \\
\hline & 50 & 7 & 3.711 & 1.537 \\
\hline & 50 & 6.5 & 3.722 & 1.576 \\
\hline & 50 & 6 & 3.754 & 1.691 \\
\hline & 50 & 5.5 & 3.843 & 2.008 \\
\hline & 50 & 5 & 4.065 & 2.781 \\
\hline & 50 & 4.5 & 4.582 & 4.480 \\
\hline & 50 & 4 & 5.747 & 7.839 \\
\hline & 50 & 3.5 & 8.371 & 12.843 \\
\hline
\end{tabular}




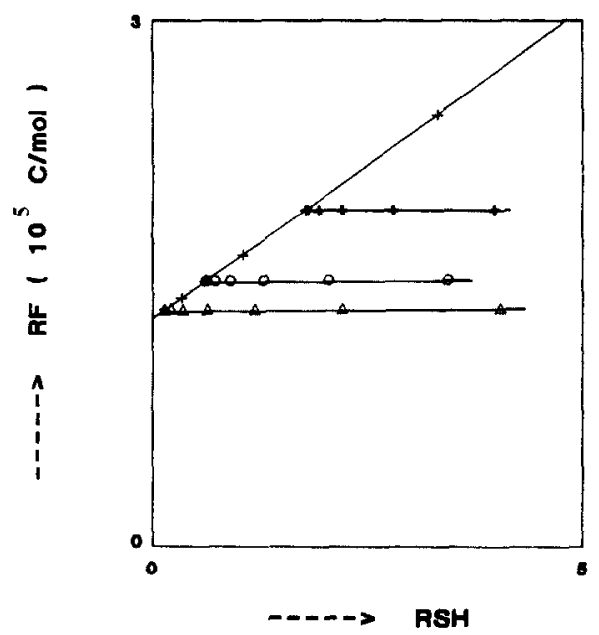

Fig. 3. Relationship between calculated RF values and RSH for $(+)$ strong monovalent and weak monovalent anionic species with absolute mobilities of $(\Delta) 70 \cdot 10^{-5}$, (O) $50 \cdot 10^{-5}$ and $(+) 30 \cdot 10^{-5} \mathrm{~cm}^{2} / \mathrm{V} \cdot \mathrm{s}$.

step height of sodium) are given in Fig. 2 for a leading electrolyte of $0.01 \mathrm{M}$ potassium hydroxide at a $\mathrm{pH}_{\mathrm{L}}$ of 5 adjusted by adding acetic acid. The relationships are given for strong and weak monovalent and divalent ions. The absolute mobilities for the weak cations are taken as $50 \cdot 10^{-5} \mathrm{~cm}^{2} / \mathrm{V} \cdot \mathrm{s}$. All the calculated data are given in Table V.

From Fig. 2, it can be seen that the RF values for the strong divalent ions are about twice those for the monovalent ions. For weak cations the RF values are lower than those for strong cations with the same RSH, as their total concentration is higher in their zones. In Fig. 3 the relationships between RF values and RSH are

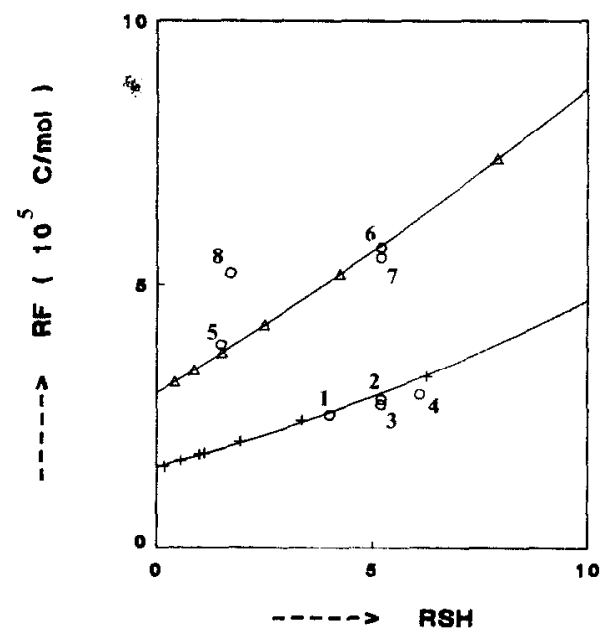

Fig. 4. Relationship between calculated RF values and RSH for strong ( + ) monovalent and $(\Delta)$ divalent cationic species. The experimentally obtained values from ref. $1(O)$ of some cationic species are included and fit the calculated values. For further explanation, see text. 
given for strong monovalent negative ions and weak monovalent ionic species for a leading electrolyte consisting of $0.01 M$ hydrochloric acid at a $\mathrm{pH}_{\mathrm{L}}$ of 6 adjusted by adding histidine.

In Fig. 4 the relationships between the calculated RF values and the calculated RSH values are given for strong monovalent and divalent ions (identical with Fig. 2), but some values from Gladdines et al. ${ }^{1}$ have been added (recalculated to $\mathrm{C} / \mathrm{mol}$ ). It can easily be seen that the values for neostigmine methylsulphate (1), imipramine hydrochloride (2), procaine hydrochloride (3) and tetracaine hydrochloride (4) fit the relationship for monovalent ions, whereas suxamethioninechloride (5), isoprenaline sulphate (6) and atropine sulphate (7) belong to the divalent ions. Gallamine triethiodide (8) must be a trivalent cation, as would be expected from its molecular structure.

\section{CONCLUSION}

It can be concluded that the determination of $\mathbf{S Z R}_{25}$ values using two standards in ITP experiments and the calculation of absolute mobilities from these S7.R 25 values lead to satisfactory results. If the absolute mobility and $\mathrm{p} K$ values of an ionic species are known, the RF values useful for quantitative determinations in ITP can be calculated.

The differences between experimentally determined and calculated RF values are about $3 \%$. Too low experimental RF values can be caused if stock solutions are prepared with impure and undried substances; the theoretical RF values are then more reliable. Too high experimental RF values mean that the effective mobility of the ionic species is lower than as expected owing, e.g., to complex formation. It is advisable always to consider the experimentally obtained RSH values as a check on these effects.

\section{REFERENCES}

1 M. M. Gladdines, J. C. Reijenga, R. G. Trieling, M. J. S. van Thiel and F. M. Everaerts, J. Chromatogr., $000(1989) 000$.

2 J. L. Beckers, J. Chromatogr., 320 (1985) 147.

3 T. Hirokawa, M. Nishino, N. Aoki, Y. Kiso, Y. Sawamoto, T. Yagi and J.-I. Akiyama, J. Chromatogr., 271 (1983) D1-D106.

1 H. Miyazaki and K. Katoh, J. Chromatogr., 119 (1976) 369.

5 F. M. Everaerts, J. L. Beckers and Th. P. E. M. Verheggen, Isotachophoresis, Theory, Instrumentation and Applications, Elsevier, Amsterdam, 1976.

6 B. Gaš, J. Zuska and J. Vacik, J. Chromatogr., 470 (1989) 69.

7 Th. P. E. M. Verheggen, J. L. Beckers and F. M. Everaerts, J. Chromatogr., 452 (1988) 615.

8 P. W. Atkins, Physical Chemistry, Oxford University Press, Osford, 1981.

9 R. C. Weast (Editor), Handbook of Chemistry and Physies, CRC Press, Boca Raton, FL, 63rd ed., 1982-183, p. D171.

0 Landolt-Bornstein, Zahlenwerte und Funktionen, 6 Aufl. Bd. II, Teil 7, Springer, Berlin, 1960.

$1 \mathrm{~J}$. Beckers, Thesis, University of Technology, Eindhoven, 1973. 